\title{
Enrique Moradiellos, Clío y las Aulas. Ensayos sobre Educación e Historia. Badajoz: Diputación de Badajoz, Área de Cultura, Departamento de Publicaciones, 2013, 315 págs.
}

Enrique Moradiellos, como otros historiadores de su generación, está comprometido con el uso público de la historia. Ha asumido una postura beligerante frente al revisionismo histórico del franquismo promovido desde cierta prensa y no ha rehuido tampoco el debate sobre los problemas que afectan a la educación en general, y a la educación histórica en particular. En este sentido, enlaza con una ya centenaria tradición, iniciada en su día por Rafael Altamira ${ }^{1}$ pero que ha tenido una limitada e intermitente continuidad hasta tiempos relativamente recientes. ${ }^{2} \mathrm{El}$ autor está alejado del modelo de profesor universitario encerrado en su reducto académico e interesado casi exclusivamente en la interlocución con sus pares y no en la función social de su trabajo. Se aparta del modelo de historiador que uno de mis maestros, Serafín Moralejo, definió en su día como ocupados en "rescatar los datos del olvido de los archivos para enterrarlo en el olvido de las bibliotecas". Por el contrario, Moradiellos ha sabido compaginar en su ya extensa obra el rigor del investigador con su preocupación con los temas educativos, la formación de profesores y el compromiso público. Quienes nos dedicamos profesionalmente a la formación del profesorado y la investigación en problemas relacionados con la enseñanza y aprendizaje de la historia, seguimos con especial interés sus aportaciones, siempre intelectualmente estimulantes. La que reseñamos ahora no es una excepción.

Clío y las aulas es un sólido ensayo en el que se reflejan algunas de las tesis críticas sobre el estado actual de la enseñanza de la historia en España y que el autor ha difundido también a través de colaboraciones en la prensa. ${ }^{3}$ Al diagnóstico pesimista de la situación de la educación y de la historia une la reivindicación de la necesidad de conocimientos históricos en la formación de una ciudadanía democrática. ${ }^{4}$ La tesis central, que se reitera a lo largo de la obra y en otros trabajos, es la de primum discere, deinde docere. Un afirmación difícilmente rebatible. Para ser un buen profesor, un maestro, no basta con tener un conocimiento profundo de una materia, se necesita algo más: todos hemos conocido y soportado soporíferos discursos de reconocidos investigadores. Pero es absolutamente imposible enseñar, ni bien ni mal, aquello que se

\footnotetext{
${ }^{1}$ Rafael Altamira, 1891, La enseñanza de la Historia (Madrid: Ediciones Akal, Madrid, 1997).

${ }^{2}$ Cabe destacar como momento de recuperación de esta tradición el debate sobre el papel de la historia en las reformas educativas de finales de los años 90 en el VII Congreso de la Asociación de Historia Contemporánea. José Ma . Ortiz de Orruño (ed.), Ayer: "Historia y Sistema Educativo” (1998): 30.

${ }^{3}$ Enrique Moradiellos en El País: "Las tribulaciones de Clío en las aulas", 17 de agosto de 2000; "Las dificultades del arte de educar", 15 de abril de 2013; y "Primero aprende, después enseña", 17 de agosto de 2013 .

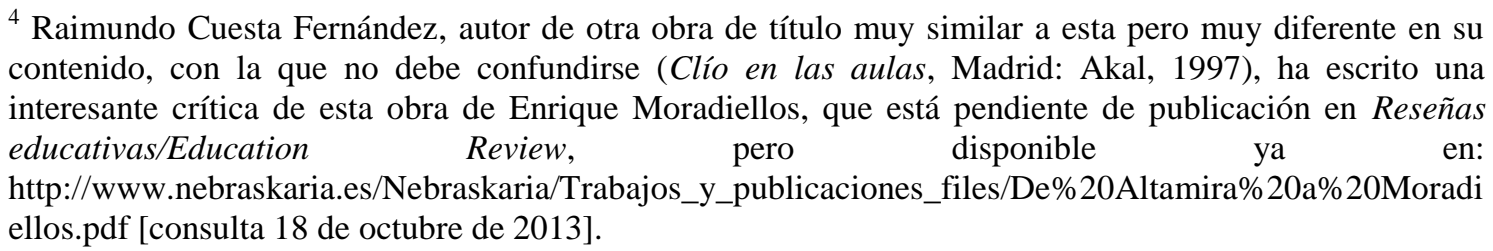


desconoce. Por eso compartimos la reivindicación del conocimiento histórico en la formación del profesorado. Un profesor de instituto que debe impartir clase de Geografía e Historia tiene la obligación de tener un conocimiento actualizado y riguroso de ambos campos de conocimientos. En este sentido, este ensayo puede ser muy útil tanto para historiadores y profesores en formación como para los que nos ocupamos de su educación, y para otros profesionales como pedagogos o psicólogos de la educación. La adquisición de nuevos conocimientos y la formación de personas competentes no se pueden realizar en abstracto, a partir de principios generales, sino a partir de conocimientos concretos y específicos.

En la primera parte de la obra, "La educación como fenómeno histórico y antropológico", se realiza una síntesis especialmente brillante al repasar la evolución histórica de la educación como actividad institucionalizada, aunque se eche en falta alguna referencia a investigaciones sobre historia social de las disciplinas escolares, como por ejemplo las de Goodson ${ }^{5}$ o Cuesta. ${ }^{6}$

En la segunda parte, "La didáctica pedagógica y los elementos del proceso educativo", es donde el ensayo adopta un perfil más polémico en su beligerancia frente a la "vacua retórica pseudo-pedagógica y su perniciosa influencia educativa" (p. 93). Estando de acuerdo en lo fundamental con la crítica a formulaciones realizadas por algunos pedagogos que se auto-atribuyen la responsabilidad (la exclusividad) de establecer las finalidades y orientaciones de la educación (pp. 91-107), la argumentación de Moradiellos merecería ser matizada para evitar cierta impresión de dogmatismo que resta eficacia al fondo de su discurso. Parece excesivo identificar a (¿toda?) la pedagogía con una filosofía "holística y formalista" que pretende "hacer tabula rasa de todo el pasado docente que ya acumula la historia de la humanidad" y cuyas "aplicaciones más extremas han venido causando un deterioro grave y persistente de los resultados educativos de las poblaciones que han tenido el infortunio de sufrirlas" (pp. 102-103). Por empezar por esto último, la percepción del deterioro de la educación es un lugar común en la tradición cultural europea de la que podemos encontrar referencias en Platón (que pone en boca de Sócrates), en Hesíodo, que vivió en el siglo VIII antes de la era, e incluso en algún escrito del antiguo Egipto de hace cuatro mil años o en una tablilla sumeria de hace cinco mil años, ${ }^{7}$ y que está en contradicción con los datos que se recogen en los indicadores sobre la educación que desde 1987 ha publicado el Centro para la Investigación e Innovación Educativa (CERI) en cooperación con la Unidad de Indicadores y Estadísticas de la Educación de la OCDE. Los avances en educación en los últimos treinta años en nuestro país (por citar un caso próximo en el que la influencia de esas corrientes pedagógicas ha sido más notable) son fácilmente constatables: eliminación del analfabetismo, ampliación de la escolarización en todos los niveles educativos como nunca había existido; avances importantes en

\footnotetext{
5 Ivor F. Goodson, Historia del curriculum. La construcción social de las disciplinas escolares (Barcelona: Pomares-Corredor, 1995).

${ }^{6}$ Raimundo Cuesta Fernández, Sociogénesis de una disciplina escolar: la historia (Barcelona: PomaresCorredor, 1997). Versión electrónica en http://www.nebraskaria.es/Nebraskaria/Trabajos_y_publicaciones_files/Sociogénesis...\%20.pdf [consulta 18 de octubre de 2013].

7 Véase http://www.buenastareas.com/ensayos/Los-Jovenes-De-Hoy-Dia/1473442.html [consulta 18 de octubre de 2013].
} 
investigación en todos los campos ... Si los jóvenes de hoy hacen más y mejores tesis doctorales que los colegas de mi generación, y la educación recibida ha sido tan nefasta por culpa de la LOGSE, la LOU y leyes similares ¿dónde y cuándo han aprendido?

Reitero mi coincidencia con el fondo de las críticas a los discursos vacuos sobre educación que con frecuencia se formulan y se recogen en las disposiciones oficiales. Pero Moradiellos dedica demasiado esfuerzo a criticar algunos aspectos, en mi opinión poco relevantes, como la desafortunada expresión de la competencia que se pretende que desarrollen los estudiantes de "aprender a aprender" (pág. 96 y ss.). Que la formulación sea improcedente por tautológica, no desvirtúa el hecho de que ser conscientes de los procesos que han hecho posible el propio aprendizaje permite favorecer una mayor autonomía personal para aprendizajes nuevos; así parecen avalarlo los resultados de diversas investigaciones. ${ }^{8} \mathrm{El}$ foco de la crítica no debería centrarse, en mi opinión, en la expresión formal de esa competencia, sino en la concepción misma de una enseñanza basada en el desarrollo de competencias con independencia de los contenidos.

Moradiellos no se refiere explícitamente a la enseñanza de competencias, un modelo implantado en la mayoría de los países integrados en la OCDE en el último decenio y en España a partir de 1997, con la LOE, aunque las críticas que formula podrían aplicarse a este nuevo marco educativo. Por ejemplo, la competencia de "aprender a aprender" es una de las ocho básicas que se recogen en la actual normativa española.

La formulación de competencias básicas como eje de la educación suele percibirse como una imposición de un modelo capitalista neoliberal promovido por organizaciones como la OCDE que ha sido pionera en hablar de la "cultura de la responsabilidad" y en la "formación a lo largo de la vida" lo que implica transferir la responsabilidad de aprender a los individuos y no a los Estados. La UE ha incorporado en gran medida esta orientación, pero sería injusto decir que se ha limitado a esto. La propuesta de formar una ciudadanía activa y la de señalar a la cohesión social como una de las finalidades del sistema educativo va más allá del pragmatismo economicista neoliberal; la dimensión laboral no es más que una de las orientaciones en las llamadas competencias clave o básicas en las legislaciones europeas y española.

Una de las primeras veces que se formuló una propuesta educativa basada en el desarrollo de competencias fue en un conocido trabajo de Noam Chomsky, ${ }^{9}$ quien relaciona el aprendizaje con el proceso de interiorización del mundo que rodea a cada individuo. Considera que esa representación interna forma parte de la identidad personal construida en estrecha relación con el contexto familiar, educativo y sociocultural. Con ella interactúa en sociedad e intenta dar respuesta a los problemas que van apareciendo a

\footnotetext{
${ }^{8}$ Entre otros: Rebollo Catalán, María Ángeles, García Pérez, Rafael, Barragán Sánchez, Raquel, Buzón García, Olga, Vega Caro, Luisa "Las emociones en el aprendizaje online", Relieve, v. 14, 1 (2008) http://www.uv.es/RELIEVE/v14n1/RELIEVEv14n1_2.htm. [Consulta 18 de octubre de 2013]. Pintrich, P. R., Smith, D. A., García, T. y Mckeachie, W. J. "Reliability and Predictive Validity of the Motivational Strategies for Learning Questionnaire (MSLQ)". Educational and Psychological Measurement, [vol.] 53, 801-813 (1993).
}

${ }^{9}$ Noam Chomsky, Aspects of the Theory of Syntax (Cambridge, Massachusetts: MIT Press, 1995). 
lo largo de su vida. Chomsky coincide con Lev Vygotsky que, como indica Moradiellos, ha explicado "que la interacción social juega un papel capital en el desarrollo de las progresivamente complejas relaciones entre palabras y conceptos de los niños" (p. 107). Las personas pueden hacerse más competentes en la medida en que saben utilizar su capacidad de percepción, los recuerdos, la estructura de pensamiento y las destrezas del lenguaje para solucionar problemas y adoptar pautas racionales de conducta.

Pero más que los referentes del constructivismo pedagógico (Vygotsky, Chomsky, Piaget, Freinet) los que han inspirado la educación por competencias que promueve la OCDE o están presentes en la LOMCE, son los teóricos de la filosofía relativista radical del llamado constructivismo filosófico (Paul Watzlawick, ${ }^{10}$ Glaserfeld, ${ }^{11}$ entre otros) que consideran que la realidad es una construcción inventada. Las críticas de Moradiellos se centran en los discursos banales de algunos pedagogos que, conscientemente o no, han asumido en buena medida este relativismo filosófico radical, que ha convertido a las metodologías, los procedimientos o las actitudes en objetivo primordial de la educación y no el conocimiento. Esta ideología está presente, por ejemplo, en la tendencia actual a sobrevalorar las TIC, meras herramientas, por encima de los conocimientos. $\mathrm{O}$ en la exclusión de conocimientos de Ciencias Sociales y Humanidades frente a las disciplinas consideradas instrumentales. La OCDE interpreta la competencia tan sólo como competitividad y parece preocuparse únicamente en evaluar aquellas que identifiquen al alumnado competitivo prescindiendo de otras capacidades y de ámbitos completos del saber como la Historia y las Humanidades. Se marginan algunas áreas de conocimiento (se las relega a la categoría de "marías") o se pide abiertamente su supresión como ha denunciado públicamente la AHA (American Historical Association) y la presidenta de la ACU (Association of American Colleges and Universities). ${ }^{12}$

Coincido con Moradiellos en que el desarrollo de competencias útiles para la vida no puede realizarse sin conocimientos específicos. Para interpretar la realidad social, cultural, económica o tecnológica hay que comprenderla, lo que significa establecer relaciones tanto temporales como causales, comparar los acontecimientos o los datos (confrontar significados) y tomar decisiones entre varias posibles. No es posible realizar estos procesos sin conocimientos sustantivos. Ser competente implica saber interpretar el mundo, saber proponer alternativas, ser capaz de argumentar. Estas operaciones no se realizan en abstracto o de manera general, con desconocimiento de cómo es y como funciona la sociedad, cómo se han ido generando y modificando las relaciones humanas a lo largo del tiempo; qué consecuencias han tenido y tienen las acciones que realizan las personas y los colectivos. Comprender los significados de las acciones humanas en diferentes contextos forma parte de la esencia del conocimiento histórico. Esto debería convertirse, en mi opinión, en el centro del debate entre quienes

\footnotetext{
${ }^{10}$ Paul Watzlawick ¿Es real la realidad? Confusión, desinformación, comunicación (Barcelona: Herder, 2002).

${ }^{11}$ Ernst von Glasersfeld Radical Constructivism: A Way of Knowing and Learning (London: Falmer Press, 1995).

12 Anaclet Pons, "Asalto a las Humanidades y a las ciencias sociales", Clionauta (29 de marzo de 2013) http://clionauta.wordpress.com/2013/03/29/asalto-a-las-humanidades-y-a-las-ciencias-sociales/ [consulta 18 de octubre de 2013].
} 
reclamamos la utilidad de los conocimientos históricos para la vida y quienes quieren reducirlos a un mero adorno culturalista, prescindible o inútil.

Algunas aportaciones de Clío y las aulas son brillantes, como la argumentación sobre la memoria histórica (pp. 158-160) o sus críticas al cuantitativismo cliométrico (p. 256), pero sería deseable una vinculación más explícita entre estos puntos de vista y los contenidos escolares en la educación obligatoria. El ensayo de Enrique Moradiellos es, ante todo, una obra incisiva, polémica, de gran brillantez en algunos momentos, sólidamente construida, bien argumentada y que mueve a la reflexión. No deja indiferente. Merece la mayor difusión que, desgraciadamente, no suele alcanzarse con publicaciones institucionales, como es el caso.

Ramón López Facal

Universidad de Santiago de Compostela

ramon.facal@usc.es

Fecha de recepción: 18 de octubre de 2013

Fecha de aceptación: 1 de noviembre de 2013

Publicado: 31 de diciembre de 2013

Para citar: Ramón López Facal, "Enrique Moradiellos, Clío y las Aulas. Ensayos sobre Educación e Historia. Badajoz: Diputación de Badajoz, Área de Cultura, Departamento de Publicaciones, 2013, 315 págs.”, Historiografías, 6 (julio-diciembre, 2013): pp. 161165, http://www.unizar.es/historiografias/historiografias/numeros/6/facal.pdf 